\title{
Motivation and Self-Esteem: Exploring Students Gender, Reasoning levels and Interest in Secondary School Chemistry
}

\author{
Ngozi P. Okafor, Raphael O. Yewande \\ Department of Science and Technology \\ Faculty of Education, University of Lagos, Nigeria
}

\begin{abstract}
Chemistry education is an engine room for economic, social and national development of any nation. Unfortunately, chemistry education in Nigeria has been plagued with mirage of problem such as poor teaching strategies, low self- esteem, poor achievement, low motivation and poor enrolment of girls, characterised by lose of interest. Some gender protagonists have established the existence of reasoning levels difference between females and males students with the males systematically and logical out-performing the girls. The purpose of this study was to determine how motivation and self- esteem as well as reasoning levels could influence secondary school girls' interest in chemistry. Four research questions guided the study. It was a correlation survey that involved 400 public co-educational secondary school girls' in Lagos State of Nigeria. Three research instruments were used in data collection. Data were analyzed using Pearson moment correlation coefficient, Analysis of Variance and multiple regression analysis The results showed a significant mean difference of reasoning levels; significant relationship among motivation, self-esteem and reasoning levels; significant composite contributions of motivation, self-esteem and reasoning levels and significant relative contributions of reasoning levels and self-esteem but motivation did not make any relative contribution in explaining secondary school girls' interest in chemistry. The study outlined numerous recommendations and concluded that appropriate learning opportunities could help in promoting girls' self-esteem and motivation in developing desired interest in chemistry across four levels of reasoning.
\end{abstract}

\section{Introduction}

Chemistry is a branch of science and an engine room for economic, social and national development of any nation Okafor [13]. Nigeria is a nation developing rapidly with increasing demand for equity in skilled manpower. Chemistry education in Nigeria has been plagued with mirage of problems such as poor teaching strategies, low self-esteem, gender differences in career aspirations, low enrolment, poor motivation and poor performance in both external and internal National Examinations Council (NECO) [7], [11], [9], [1], [15], [8]. Barnes, Mcinerney \& Marsh have observed that the intellectual potentials of females remain untapped in scientific knowledge; therefore, if more females are to study courses in physical sciences, their current underrepresentation will be reversed [4]. It is a common knowledge that the traditional attitude of Nigerian parents to the education of their children is to invest in boy-child. Influenced by the traditional early child role models, many boys are exposed to experiences with tasks that are mechanical, scientific and technical in nature such as fixing a car or building a robot car but reverse is the case for girls.

These early experiences promote the development of stronger self-esteem expectations among boys towards future careers than girls. The paucity of girls in sciences and worst in chemistry is well documented [11]. The vast majority of girls who attended schools earlier did not offer science courses except, perhaps, biology, hygiene and home management or domestic science while boys offered wide range of courses in engineering, chemistry, medicine and further mathematics.

The choice of subjects was as a result of socialization and stereotyping that some occupations are feminine and others masculine. Interestingly, female students were found to have outperformed the males at the Nigerian Television Authority (NTA), Channel 10 Face the State quiz competition in chemistry. Barnes, Mcinerney \& Marsh explored sex differences in enrolment patterns of 449 high school students in Sydney [4]. The result showed that males were more interested in studying chemistry than the females [5]. Conducted a study on third-grade teachers' gender-related beliefs and behaviours and found that teachers' attitude to science significantly correlate with students' achievement. Okafor has argued that reasoning levels could play a vital role in fostering students' interest in chemistry [12]. This study has examined motivation, self-esteem and levels of reasoning on secondary school girls' interest in chemistry. 


\section{Motivation, Self-esteem and Reasoning levels of girls in science (chemistry)}

Science education researchers have attempted to explain how students learn science and the emotions that trigger the learning process [6], [5]. Motivated students enjoy learning sciences and believe in their ability to take responsibility on their learning. Weimer stated that motivation favours students that have difficulties in coping with difficult chemistry concepts during teaching-learning process. He also investigated how gender moderates students' emotions using praises but found that praises motivate girls, but with little influence on boys [15].

In the same vein at a television presentation on self-esteem, the facilitators summarized that Low self-esteem is characterized with the feelings of unhappiness, feelings of anxiety, feelings of inferiority or superiority, impatience or irritation with self or others and externally oriented goals while high self-esteem is characterized with responsibility, goal commitment and genuineness. The contributors agreed that positive self-esteem could be enhanced through the elimination of negative self-talk, recognizing strengths and selfworth. Bandura posited that women and men think differently in many ways and develop different expectations about themselves through the four sources of self-efficacy [3].

Piaget's work on cognitive or reasoning levels believes that child's development occurs through a continuous transformation of thoughts and processes [14]. He explained that all children pass each stage before the next one without skipping any. This implies that older children or adults who do not pass through early stage processes may manifest it at their older life. Level of reasoning or cognitive development is the level of human mental development as individual progresses from a state of not knowing to the level by which knowledge and skills are acquired and utilized [13]. The levels are in four stages of Piaget's mental development theory (Sensory-motor, 0-2years; pre-operational or intuitive, 2-7 years ;concrete operations, 7-12 years and formal operations, 12 years \& above) [14]. This study considered two last stages that are briefly discussed below. At the concrete reasoning stage, abstract- hypothetical thinking is not yet developed in the student because he or she solves problems that apply to concrete events or objects. Children in this stage commonly experience difficulties with figuring out logics in their heads. At the formal reasoning stage, abstract thought emerges where the student begins to consider possible outcomes and consequences of actions. Problem-solving is demonstrated when students use trial-and-error to solve problems. At this stage, the ability to systematically solve a problem in a logical and methodological way emerges. This is often required in science and mathematics. Piaget believed that reasoning is grounded in the interface between mind and environment and the result is working towards a balance between mental schemata and the requirements of the environment [14]. Okafor and Lawson found Piaget's instrument applicable in investigating students' levels of reasoning with respect to any field of study and any group of students [13], [10]. The instrument discriminated among the students' levels of reasoning, thus making it possible to determine who benefits most from chemistry education and science in general. The researchers therefore believe that knowledge of girls' reasoning levels could provide adequate information on the effective ways of boosting their self-esteem and motivating their interest which have implication for chemistry education theory and practice.

\subsection{Problem}

Despite the prime position chemistry occupies in National development, the teaching and learning of secondary school chemistry has been bedevilled with mirage of problem that has led to poor enrolment and loss of interest by girl-child which is characterised by fear and anxiety. The National Examinations Council (NECO) results in chemistry over five years (2009-2014) have shown increasing gap on the performance of girls in favour of boys. This observed gap in girls' performance may be related to lack of interest and low motivation by the teachers. Some gender protagonists have also established the difference between the reasoning levels of females and males with the males showing more understanding in the late formal reasoning level. Garg \& Gupta explained that poor performance and low self-esteem have direct influence on students' interest in chemistry [8]. Research studies have also stated that poor self-esteem, negative attitude, poor teaching strategies and low critical thinking could lead to superficial learning that does not enhance interest in chemistry [1], [4], [12] [15]. However, several attempts have been made by chemistry educators to enhancing girls' interest on secondary school chemistry but these have yielded little or no improvement. The main purpose of this study therefore was to determine how motivation and selfesteem could influence secondary school girls' interest in chemistry. It would also establish the extent to which the girls' reasoning levels could contribute in that direction.

\subsection{Research Questions}

Four research questions guided the study as stated below.

(1) At what reasoning levels do secondary school girls have interest in chemistry?

(2) What are the relationships between motivation and self-esteem on secondary school girls' reasoning levels and interest in chemistry?

(3) What are the composite contributions of motivation, self-esteem and reasoning levels of secondary school girls' interest in chemistry? 
(4) What are the relative contributions of motivation, self-esteem and levels of reasoning on secondary school girls' interest in chemistry?

\section{Methodology}

Correlation survey design guided the study. This design was deemed suitable as it is capable of answering the research questions posed as well as technically accounting for the variance contribution to the dependent variable in this study. Stratified and simple random sampling techniques were used in selecting Four Hundred Girls of Senior Secondary School Two ( SSS II) in public co-educational schools from two out of six Educational Districts (Ten schools from each District) offering chemistry in Lagos, State of Nigeria. The selected schools had adequately equipped laboratory, science club for cocurricular activities with science teachers' certified by Teachers Registration Council of Nigeria (TRCN) as professionals.

Three research instruments were used in data collection. Motivation and Self-Esteem Inventory (MSE), Cognitive Development Test (CDT) and Interest in Chemistry (INC). MSE was developed by the authors and had three sections. Section one had three items (Class, age and gender) on respondents bio-data while sections two and three involved twenty items in each which elicited information on a Four Point Likert Scales: Strongly Agree (SA); Agree (A); Strongly Disagreed (SD) and Disagree (D).The instrument was face and content validated by a proficient evaluator in psychology and was trial tested on 100 girls in two private schools that were not part of the sample. The reliability coefficient of 0.84 was obtained using Cronbach Alpha. CDT was 20 short answer-items constructed by the authors and drawn from acids, basis and salts content areas of SS1 and SS11 chemistry.

The content and construct validity of the CDT was determined by expert opinion of a science evaluator and two senior research fellows in chemistry education. The items were adjudged adequate for administration. The items were trial tested on 100 chemistry girls of two private schools with difficulty indices that ranged from 0.4 to 0.6 and discriminating indices ranging from 0.1 to 0.3 . Using Kuder-Richardson formula 20, reliability coefficient of 0.79 was obtained. The essence of CDT was to assess girls' reasoning levels by matching their responses on Piagetian [14] developmental stages as stated in Table 1
Table 1: Piaget and Researchers Score Range and Piaget's Developmental Stages

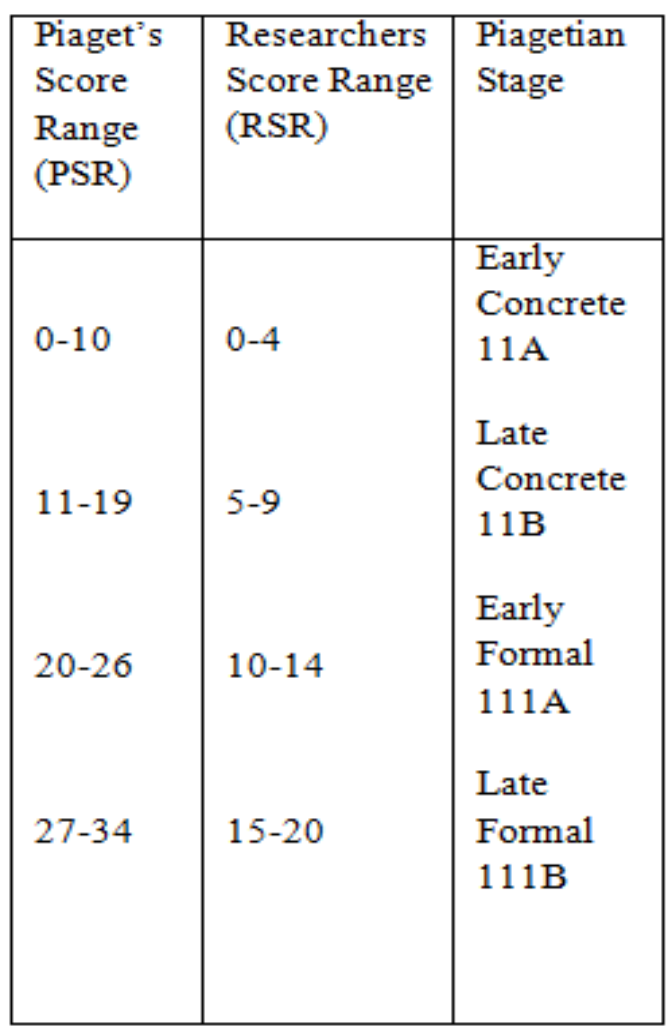

Matching of students' performance on Piaget's stages was previously used in United States of America and was adapted for Nigerian students by Okafor [13] in predicting performance outcomes at different levels of cognitive development. The results obtained are not significantly different from the status quo. According to Anastasi [2] most ability tests at cognitive or reasoning levels are designed to assess as accurately as possible each individuals level of attainment in a particular concept.

Table 2. Piaget and Researchers Score Range and Piaget's Developmental Stages

\begin{tabular}{|l|l|l|}
\hline $\begin{array}{l}\text { Piaget's } \\
\text { Score } \\
\text { Range } \\
\text { (PSR) }\end{array}$ & $\begin{array}{l}\text { Researchers } \\
\text { Score } \\
\text { Range } \\
\text { (RSR) }\end{array}$ & $\begin{array}{l}\text { Piagetian } \\
\text { Stage }\end{array}$ \\
\hline $11-19$ & $5-9$ & $\begin{array}{l}\text { Late } \\
\text { Concrete } \\
11 \mathrm{~B}\end{array}$ \\
$20-26$ & $10-14$ & $\begin{array}{l}\text { Early } \\
\text { Formal } \\
111 \mathrm{~A}\end{array}$ \\
& & \\
& & \\
\hline
\end{tabular}

The responses of the Testees after the CDT were matched on Researchers' Score Range and Piagetian Stages as shown in Table 2. The results obtained showed that majority of girls were in late concrete 
and early formal stages with very few on early concrete and late formal stages respectively. Cognitive Development Test (CDT) items were dichotomously scored. Each correct response attracted one (1) mark and a wrong response attracted zero (0). The maximum obtainable score for CDT was 20. The respondents' scores on CDT were used to classify them into two levels of cognitive development as shown in Table 2. In addition, Interest in Chemistry (INC) was designed and validated by the researchers. A Cronbach alpha of 0.76 was obtained showing evidence of internal consistency. The instrument consisted of 32-items and subjects were to respond to each on a Four Point Likert Scale. Strongly Agree (SA); Agree (A); Strongly Disagreed (SD) and Disagree (D).

In scoring the responses for MSE and INC, each item that reflected positive interest was given a score of Four(4) for 'Strongly Agree' and response progressing downward to a score of One (1) for a Strongly Disagree response. The scoring procedure was reversed when a response of 'Strongly Disagree' indicated a positive interest. On the whole, the maximum scores were 128 . The instruments administrations lasted for four weeks and were done by the researchers with assistance from the respondents' class teachers who were remunerated with token gifts. Data were analyzed using descriptive statistics of mean and standard deviation. Inferential statistics of Pearson moment correlation coefficient, analysis of variance and multiple regression analysis were also employed in the analysis.

\section{Results}

\section{Research Question 1}

(1)At what reasoning levels do secondary school girls have interest in chemistry?

Table 3:One-Way Analysis of Variance of Girls' Interest in Chemistry Based on Levels of Reasoning

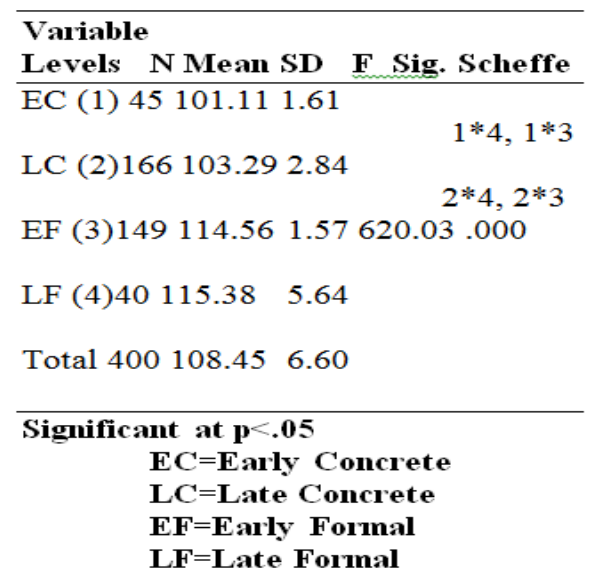

Table 3 indicates that there was a significant mean difference in students' interest in chemistry based on their levels of reasoning $(\mathrm{F}(3,396)$ $=620.03, \mathrm{p}=.000)$. In order to determine where significant differences exist, a pair-wise comparison using Scheffe Post-hoc was employed. Scheffe-post hoc was considered most suitable because of the equal number in the various levels of reasoning and the fact that it is the least conservative in yielding to statistical significance. Scheffe post-hoc indicates that there was a statistical significant difference between early concrete and late formal, early concrete and early formal, late concrete and early formal as well as late concrete and late formal. However, no statistical mean difference was found between the pair-wise comparisons of early concrete and late concrete on one hand as well as early formal and late formal on the other hand. This explained that secondary school girls' interest in chemistry was specifically at the reasoning levels of late concrete and early formal because of a noticeable significant difference.

\section{Research Question 2}

What are the relationship among motivation, selfesteem and levels of reasoning on secondary school girls' interest in chemistry?

Table 4: Pearson Correlation of Predictors with Secondary School Girls’ Interest in Chemistry

\begin{tabular}{|c|c|c|c|}
\hline (1) & (2) & ((3) & (4) \\
\hline 1 & \multicolumn{3}{|c|}{$650 * * * .296 * * * .830 * * *$} \\
\hline $2.560 * * *$ & 1 & $.151 * *$ & $.650 * * *$ \\
\hline $3.296 * * *$ & $.151 * *$ & 1 & $.230 * * *$ \\
\hline \multicolumn{4}{|c|}{$4.830 * * * .650 * * * .230 * * \quad 1$} \\
\hline \multicolumn{4}{|c|}{$\begin{array}{l}\mathbf{1}=\text { Interest } \quad 2=\text { Motivation } \quad 3=\text { Self- } \\
\text { esteem } 4=\text { Levels of Reasoning } \\
<.001=* * *<.01=* *<.05 * \text { Significant } \\
\text { at } \mathbf{p}<.05\end{array}$} \\
\hline
\end{tabular}

Table 4 shows that there was a significant positive relationship between motivation and girls' interest in chemistry $(\mathrm{r}=.650, \mathrm{~N}=400, \mathrm{p}=.000)$. Also, there were significant positive relationships between self-esteem and levels of reasoning on girls' interest in chemistry (Self-esteem: $r=.296, N=400, p=.000$; levels of reasoning: $r=.830, N=400, p=.000$ ). There were positive significant relationship among the independent variables as shown in Table 4 but they were not as high as 0.800 to detect the presence of excessive correlations of the predictors which gives rise to multicollinearity. 


\section{Research Question 3}

What are the composite contributions of motivation, self-esteem and levels of reasoning on secondary school girls' interest in chemistry?

Table 5: Model Summary-Analysis of Variance Table in Multiple Regression for Secondary School Girls’ Interest in Chemistry

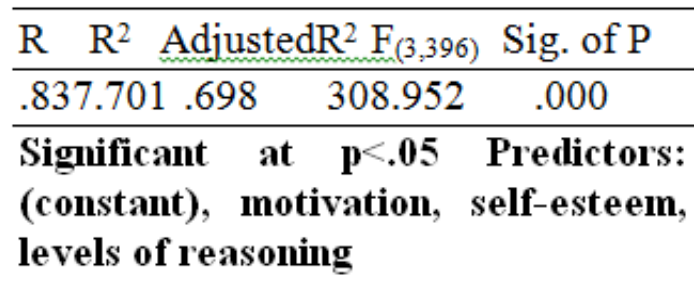

\section{Research Question 4}

What are the relative contributions of motivation, self-esteem and levels of reasoning on secondary school girls' interest in chemistry?

Table 6: Coefficients Table of Multiple Regression for Secondary Girls’ Interest in Chemistry

\begin{tabular}{llllll} 
& $\begin{array}{l}\text { Unstanda } \\
\text { rdised } \\
\text { Coefficie }\end{array}$ & $\begin{array}{l}\text { Std. } \\
\text { Coeffi } \\
\text { cient }\end{array}$ & & \\
nt & & & & \\
Mode & B & SE & Beta & T & $\begin{array}{l}\text { Si } \\
\text { g. }\end{array}$ \\
\hline Const & 73. & 5.1 & & 14. & .0 \\
ant & 659 & 04 & & 43 & 0 \\
Cogni & 6.2 & 29 & .780 & 21. & .0 \\
tive & 65 & 5 & & 23 & 0 \\
Dev. & & & & & \\
Motiv & .06 & .06 & 036 & 1.0 & .3 \\
ation & 5 & 5 & & 0 & 2 \\
& & & & & \\
Self- & .25 & .06 & .112 & 3.9 & .0 \\
estee & 0 & 3 & & 5 & 0 \\
m & & & & &
\end{tabular}

\section{Significant at $p<.05$}

Table 6 shows that there was a significant relative contribution of reasoning levels on secondary school girls' interest in chemistry $(\mathrm{t}=21.23, \beta=.780$, $\mathrm{p}=.000$ ). The beta value indicates that for every one unit change in secondary school girls' interest in chemistry, there was a positive increase of 0.780 unit in the levels of reasoning. Motivation did not significantly contribute in explaining secondary school girls' interest in chemistry $(\mathrm{t}=1.00, \beta=.036$, $\mathrm{p}=000$ ), Self-esteem relative contribution to the prediction model of secondary school girls' interest in chemistry was significant $(\mathrm{t}=3.95, \beta=.112$, $\mathrm{p}=.000$ ). The beta value indicates that for every unit change in secondary school girls' interest in chemistry, there was a positive increase of 0.112 unit on self-esteem.

\subsection{Discussion}

Four research questions guided the study. Research question 1 shows that it was at the late concrete and early formal levels of reasoning that girls' interest in chemistry was centered. This contradicts Paget's work that child's development occurs through a continuous transformation of thoughts and processes, implying that older children who do not pass through early stage process that is characteristic of younger children may manifest it at any particular point of their older life [14]. It was observed that girls reasoning were mainly at the late concrete and early formal levels, thus skipping early concrete level. This entails that their abstracthypothetical thinking for solving chemistry tasks in a logical way has developed with consequences of actions or cause-effect knowledge demonstrated in solving work problem in chemistry. However, girls can conveniently compete with boys in all fields of study because they have not demonstrated intellectual inferiority. This corroborates with Okafor work which explained that adolescents irrespective of their age differences could benefit from chemistry education when positively motivated. This has described a strong connection between critical reasoning and positive interest in chemistry [13].

Research question two shows a significant relationship among motivation, self-esteem, levels of reasoning in relation to secondary school girls' interest in chemistry. This finding is validated by the previous studies of Hidi and Renninger who emphasized that motivated students enjoy learning sciences and believe in their ability to take responsibility for their learning [9]. The finding also supports Weimer investigation that praises motivate girls excellence but with little influence on boys [15]. The self-esteem demonstrated by girls on their interest in chemistry contradicts the research reports of Ainley and Nnaka and Anaekwe which explained that role socialization pattern could lead to gender differences in self-esteem and self-confidence in science career domains [1], [11]. When the girls were exposed to similar chemistry concepts, the feelings of anxiety, inferiority or superiority were devoid in solving the tasks presented to them in chemistry. This also validates the work of Hidi and Renninger who maintained that each phase of interest development reflects what the individual has stored in its cognitive structure [9].

Research question three shows a significant composite contribution of motivation, self-esteem and levels of reasoning when combined together on girls' interest in secondary school chemistry. All these psychological variables effectively predicted 
girls' interest which therefore, demands their application in the classroom settings by all science teachers to adequately promote and foster girls' interest in sciences (chemistry). This supports the researchers' assertion that creating cultural thought, tolerance, positive self-esteem, cooperation and love among chemistry students could foster and sustain their interest during the classroom activities.

Research question four has also shown significant relative contributions of self-esteem and reasoning levels on secondary girls' interest in chemistry. Not much contribution is evidenced with motivation. There would be need to boost girls self-esteem and ensure that their reasoning levels are grounded in the interface between the mind and environment as to strike a balance between mental schemata and the requirements of the environment.

This also validated Okafors work which argued that reasoning level is central to determining how pedagogical strategies elicits students' spontaneous responses in a learning environment but contradicts Hidi and Renninger whose studies stipulated that when females are well-prepared, have confident with positive self-esteem and high motivation, that achievement and interest gaps would be bridged [13], [9]. Therefore chemistry teachers should strengthen the above virtues among the students since the school environment that enhances girls' self-esteem with adequate motivation could foster critical reasoning of students beyond early formal stage.

\section{Recommendation}

Based on the findings of this study, the following are recommended:

- Positive self-esteem should be promoted among secondary school girls through formation of chemistry clubs and quiz competitions.

- Chemistry teachers should ensure active participation of girls during teaching and learning process.

- Periodic seminars should be organized by science education stakeholders on the teaching and learning of chemistry at home.

- Girls should be given more chemical tasks that require logical reasoning at the late formal reasoning level.

- Pedagogical teaching strategies that promote girls' interest in chemistry such as cooperative learning, conceptual change approach and peerassisted learning should be used always by the chemistry teachers in the classrooms and during practical classes.

- Periodic symposium should be organized by the school authority on how girls studying chemistry should boost their strengths, self-worth and imbibing 'I can do it attitude' in venturing into scientific fields that are perceived to be male preserved.

- Secondary school chemistry teachers should motivate girls with praises and other incentives as ways of boosting their self-esteem to ensure that their reasoning levels are grounded in the interface between mind and environment as to strike a balance between mental schemata and the requirements of the environment.

\section{Conclusion}

Nigerian secondary school chemistry curriculum is structured to develop in the students, irrespective of gender, the acquisition of knowledge, skills, appreciation and its interrelatedness with other sciences in the society. These indicate that the ideas students bring from home to the school should be effectively monitored to ensure that those with low self-esteem and poor motivation are given individualistic attention during classroom activities. To meet this challenge, schools must be transformed in a way that girls and boys acquire creative reasoning skills that are sequential across the four levels of reasoning as indicated by Jean Piaget. The findings provided in this study have shown that girls reasoning levels were at late concrete and early formal levels of reasoning with significant relationship among motivation, self-esteem and reasoning levels in predicting secondary school girls' interest in chemistry.

This study has shown that psychological variables which are affective in nature do not exist in isolation but rather correlate and interact with reasoning levels in fostering students' interest in chemistry. There would be need to ensure that psychological variables such as self-esteem and motivation are strengthened and sustained in a bid to fostering secondary school girls' interest in chemistry. Finally, appropriate learning opportunities could help in promoting girls' self-esteem and motivation as to develop their desired interest in chemistry across four levels of reasoning beyond secondary school.

\section{Reference}

[1] Ainley, M., (2006). Connecting with learning: motivation, affective and cognition in interest processes Educational Psychology Review. 18(4) pp 391-405.

[2] Anastasi, A., 'Psychological testing'.Fourth Edition Macmillan Publishing.Co., Inc. New York: 1976. pp 8993.

[3] Bandura, A., 'Social foundations ofthought and action: A social cognitive theory' Prentice-Hall. Englewood Cliffs, NJ: 1986.

[4] Barnes, G., D. M. Mcinerney and H.W. Marsh, (2005). Exploring sex differences in science enrolment intentions: An application of the general model of academic choice. Australian. Educational Research, 32(2), pp. 1-23.

[5] Berg, C. and R. Anders, (2005). Factors related to observed attitude change toward learning chemistry among university students, Chemistry Education Research and Practice, 6 (1), pp. 
[6] Betiku, O., (2002).Cognitive styles and academic performance in chemistry. The Nigeria Teacher Today 10 (1\&2). pp 37-52.

[7] Eriba, J and S. Ande, (2006). Gender differences in achievement in calculating reacting masses from chemical equations among secondary school students in Makurdi metropolis. Educational research and reviews journal, 1 (6), pp. 170-173.

[8] Garg, K.C. and B.M. Gupta, (2003). Decline in science education in India. A case study of undergraduate level students. Current Science, 84(9), pp.1198-1201.

[9] Hidi, K. and K. Renninger, 'The four-phase model of interest in development. Educational Psychology.

41(2). 2006, Pp. 111-127.Lawson, A.E

[10] Formal reasoning, achievement and intelligence. Science Education. Vol. 66 (1), 1982.pp. 77-83.

[11] Nnaka C.V. and M.C. Anaekwe, Sustaining Students' Interest in Science, Technology and Mathematics (STM) through Gender-fair Instructional Behaviours: Implication for Professionalization of teaching in Nigeria. Proceedings of the 46th Annual STAN conference 2005 pp. 229.

[12]Okafor, N. (2013). Assessment of critical thinking abilities acquired by senior secondary school chemistry students International Journal of Multicultural Education (IJME). Publication of Faculty of Education, University of Lagos; Sibon Books Ltd. 6(1), pp. 51-62.

[13] Okafor, N. Effect of co-operative learning and conceptual change pedagogical strategies on students' achievement and attitude towards chemistry. A Doctoral Degree Thesis. International Centre on Educational Evaluation (ICEE), Institute of Education, University of Ibadan. 1999.

[14].Piaget, J Intellectual evolution from adolescent to adulthood. Human Development. (15). 1972. pp. 60-68

[15] Weiner, B. (2000). Interpersonal and intrapersonal theories of motivation from an attribution perspective. Education Psychology Review. 12(1), pp. 1-14 